\title{
Correction to: TIRR: a potential front runner in HDR race-hypotheses and perspectives
}

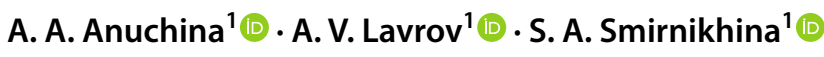

Published online: 4 January 2021

(c) Springer Nature B.V. 2021

\section{Correction to: \\ Molecular Biology Reports (2020) 47:2371-2379 \\ https://doi.org/10.1007/s11033-020-05285-x}

The Acknowledgment text has been updated.

Acknowledgements The sections were supported: "The interplay of the main factors managing repair of DNA DSB" by the grant of the Russian Science Foundation (Agreement 17-75-20095); "The role of chromatin condition in the repair pathway choice" by the Russian Academy of Sciences (Program "Fundamental researches for biomedical technologies"); "The first histone-masking protein. Structure and homology" by the state assignment of Ministry of Science and Higher Education of Russian Federation; "TIRR role in DNA repair" by the grant of the Russian Foundation for Basic research (Agreement 19-34-90130).
Publisher's Note Springer Nature remains neutral with regard to jurisdictional claims in published maps and institutional affiliations.

The original article can be found online at https://doi.org/10.1007/ s11033-020-05285-x.

\footnotetext{
A. A. Anuchina

arinate@mail.ru

1 Laboratory of Genome Editing, Federal State Budgetary

Institution "Research Centre for Medical Genetics",

Moskvorechie, 1, Moscow, Russia 115522
} 